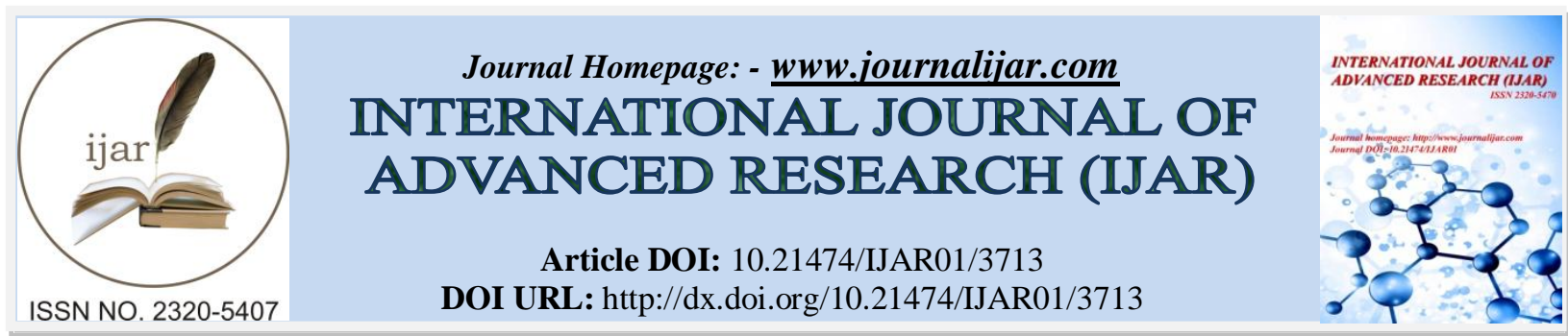

RESEARCH ARTICLE

\title{
STUDY TO ANALYSE AND COMPARE THE QUALITY OF LIFE IN PATIENTS OF ADVANCED STAGE LUNG CANCER UNDERGOING TWO DIFFERENT MODALITIES OF TREATMENT.
}

1. Department of Radiotherapy, JIPMER, India.

Divyesh Kumar ${ }^{1}$ and Veera. $K^{2}$.

2. Department of PSM, JIPMER, India.

\section{Manuscript Info}

Manuscript History

Received: 15 January 2017

Final Accepted: 08 February 2017

Published: March 2017

Key words:-

Lung ancer,Radiation,Advancestage

\begin{abstract}
Lung cancer is the leading cause of cancer-related death worldwide. Most patients are generally diagnosed with advanced-stage of disease and oftenly are associated with dismal prognosis. Multimodality approach is thestandard of care for managing such patients. Quality of life (QOL)might vary with the type of treatment received. QOL thus is an important parameter to measure. Given that lung cancer is one of the common cancers world-wide, the implications of focusing on quality of life require to be understood. Thus we in this study retrospectively have tried to analyse the effect on quality of life in patients of advanced stage carcinoma lung undergoing chemotherapy and radiation therapy either concurrently or sequentially.
\end{abstract}

Copy Right, IJAR, 2017,. All rights reserved.

\section{Introduction:-}

Lung cancer is one of the leading causes of mortality and morbidity worldwide. In view of high morbidity and symptom burden, quality of life (QOL) is an important parameter to measure. Incorporation of the assessment of QOL as part of daily oncology practice may enhance current treatment strategies for cancer patients [1]. In addition, enhanced understanding of the common QOL of patients enables to improve the clinical care of patients [2].We in this study have tried to analyse and compare the quality of life in patients of advanced stage lung cancer undergoing two different modalities of treatment.

\section{Material and Method:-}

Data of 78 patients of advanced staged (stage III A \& B) carcinoma lung was collected, analysed retrospectively and was randomised according to the treatment received followed by QOL scoring using Quality of life Questionnaire Core 30 (QLQC30) and Lung Cancer Module (LC13),version 3.0. Results were subsequently analysed statiscally using SPSS software version 20.Flow chart illustrating the work flow is shown in Fig-1. 
Fig-1.Flow chart depicting work flow.

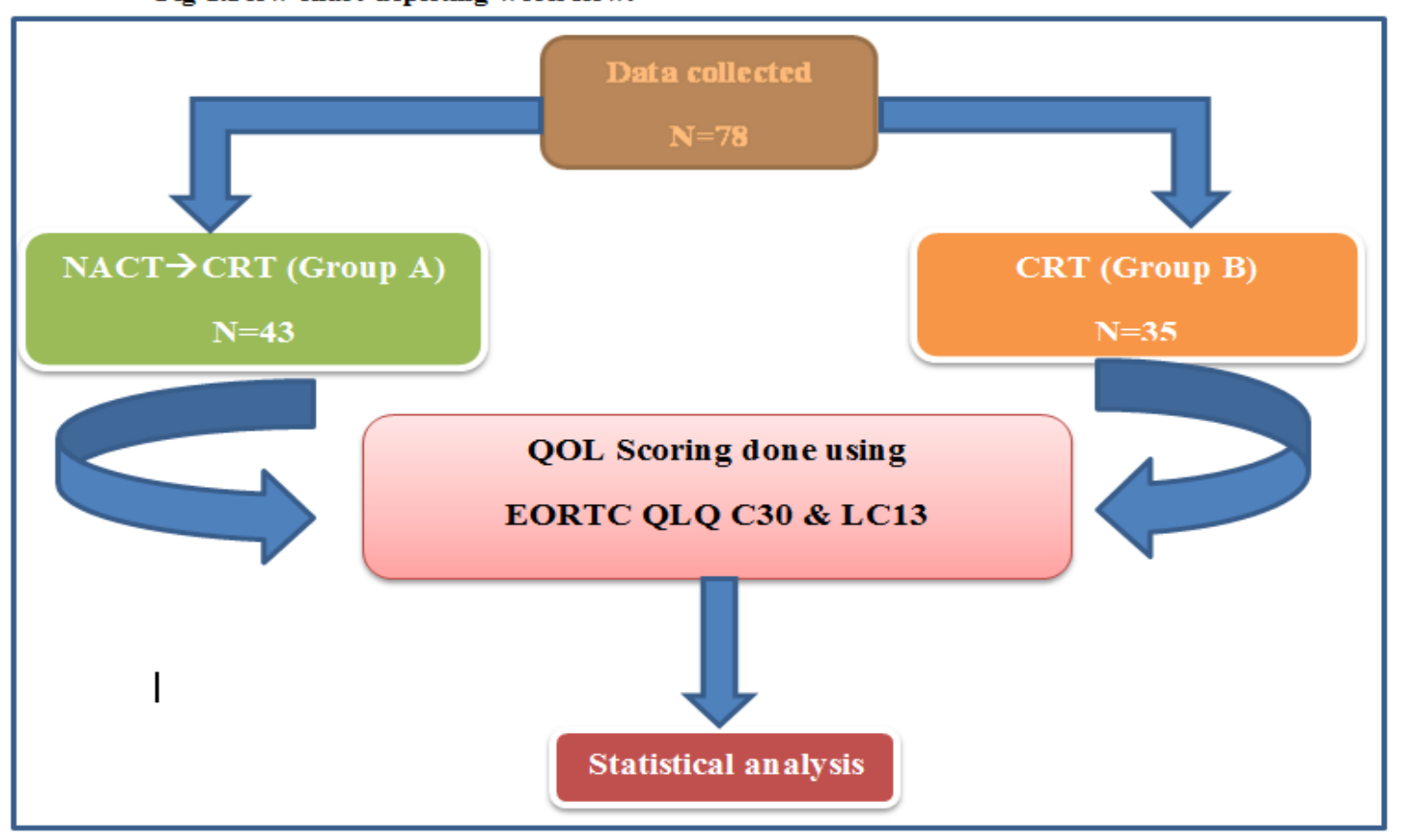

Result:-

Table 1:- Baseline characteristics of 78 lung cancer patients.

\begin{tabular}{|c|c|c|c|}
\hline Characteristic & Categories & Number & Percent \\
\hline \multirow[t]{3}{*}{ Age at presentation (years) } & Mean & 56 & \\
\hline & Median & 58 & \\
\hline & Range & $42-74$ & \\
\hline \multirow[t]{3}{*}{ Patients } & Group A & 43 & 55.12 \\
\hline & Group B & 35 & 44.88 \\
\hline & Total & 78 & 100 \\
\hline \multirow[t]{2}{*}{ Stage } & Stage III A & 47 & 60.25 \\
\hline & Stage III B & 31 & \begin{tabular}{|l|l}
39.75 &
\end{tabular} \\
\hline \multirow[t]{2}{*}{ Treatment History } & NACT $\rightarrow$ CRT & 43 & 55.12 \\
\hline & CRT & 35 & 44.88 \\
\hline
\end{tabular}

Table 2:- Baseline QoL (C30) scores of 78 lung cancer patients.

\begin{tabular}{|c|c|c|c|c|}
\hline QLQ-C30 Scale & Mean & Median & SD & Range \\
\hline Global & 53.6 & 58.3 & 26.3 & $0-100$ \\
\hline Physical & 68.7 & 73.3 & 25.5 & $0-100$ \\
\hline Role & 58.9 & 66.7 & 34.3 & $0-100$ \\
\hline Emotional & 64.1 & 66.7 & 25.8 & $0-100$ \\
\hline Cognitive & 74.9 & 83.3 & 25.9 & $0-100$ \\
\hline Social & 61.2 & 66.7 & 32.9 & $0-100$ \\
\hline Fatigue & 46.8 & 44.4 & 28.4 & $0-100$ \\
\hline Nausea/Vomiting & 14.5 & 0 & 22.2 & $0-100$ \\
\hline Pain & 37.1 & 33.3 & 32.8 & $0-100$ \\
\hline Dyspnea & 37.6 & 33.3 & 33.6 & $0-100$ \\
\hline Insomnia & 39.9 & 33.3 & 33.5 & $0-100$ \\
\hline Appetite Loss & 31.3 & 33.3 & 34.1 & $0-100$ \\
\hline Constipation & 24.2 & 0 & 31.3 & $0-100$ \\
\hline Diarrhea & 9.9 & 0 & 19.7 & $0-100$ \\
\hline
\end{tabular}


Table 3:- Baseline QoL (LC13) scores of 78 lung cancer patients.

\begin{tabular}{|l|l|l|l|l|}
\hline LC13 & Mean & Median & SD & Range \\
\hline Cough\&Hemoptysis & 58.9 & 66.7 & 34.3 & $0-100$ \\
\hline Shortness Of Breath & 64.1 & 66.7 & 25.8 & $0-100$ \\
\hline Swallowing,Tingling & 74.9 & 83.3 & 25.9 & $0-100$ \\
\hline Pain \& Pain relief & 61.2 & 66.7 & 32.9 & $0-100$ \\
\hline
\end{tabular}

Table 4:- Multivariate Cox regression analysis for QoL function and symptom scales.

\begin{tabular}{|l|l|l|l|}
\hline QoL Domain & HR & 95\% CI & P-value \\
\hline Physical & 0.99 & 0.986 to 0.994 & $<0.001$ \\
\hline Role & 0.999 & 0.995 to 1.002 & 0.5 \\
\hline Emotional & 1.001 & 0.997 to 1.005 & 0.58 \\
\hline Cognitive & 1 & 0.996 to 1.003 & 0.8 \\
\hline Social & 1 & 0.996 to 1.003 & 0.85 \\
\hline Fatigue & 0.996 & 0.992 to 1.001 & 0.16 \\
\hline Nausea/vomiting & 0.997 & 0.993 to 1.001 & 0.2 \\
\hline Pain & 1.002 & 0.999 to 1.005 & 0.16 \\
\hline Dyspnea & 1.001 & 0.999 to 1.004 & 0.34 \\
\hline Appetite Loss & 1.003 & 1.000 to 1.005 & 0.07 \\
\hline Constipation & 1 & 0.998 to 1.003 & 0.73 \\
\hline Diarrhea & 1.003 & 0.999 to 1.006 & 0.16 \\
\hline
\end{tabular}

\section{Discussion:-}

In our study we tried to evaluate and compare the effect on QOL in patients receiving either modality of treatment $\mathrm{i}, \mathrm{e}$ NACT $\rightarrow$ CRT or CRT alone in patients of advanced stage carcinoma lung and found that QOL is better off in patients receiving CRT alone, this probably could be due to more toxicity profile with chemotherapy received by patients in both neoadjuvant as well as in concurrent setting in group A.Study done by J. A. Langendijk et al showed chemoradiation was superior to chemotherapy alone with respect to survival and HRQoL at the expense of more hospital admissions due to toxicity[4].In an another study done by Shintaro Traumani et al, they found that pulmonary rehabilitation program for patients with non-small cell lung cancer undergoing induction chemoradiotherapy seems to improve respiratory function. It is particularly recommended for smokers and patients with respiratory impairment [5]. In a study done by Bottomley A, radical radiotherapy offers palliation of respiratory symptoms and improved QoL in a substantial proportion of patients with NSCLC who have relatively good prognostic features [6].

\section{Conclusion:-}

Quality of life is better off with single modality treatment when compared to double modality of treatment.

\section{References:-}

1. Gralla RJ and Thatcher N: Quality-of-life assessment in advanced lung cancer: Lung Cancer 46: S41-S47, 2004.

2. Mystakidou $\mathrm{K}$ et al: Assessment of anxiety and depression in advanced cancer patients and their relationship with quality of life. Qual Life Res 14: 1825-1833, 2005.

3. Gridelli C, Perrone F, Nelli F et al. Quality of life in lung cancer patients. Ann Oncol 2001;12 Suppl 3:S21-5.

4. Concurrent palliative chemoradiation leads to survival and quality of life benefits in poor prognosis stage III nsclc: British Journal of Cancer (2013) 109, 1467-1475.

5. J. A. Langendijk et al Prospective Study on QOL Before and After Radical Radiotherapy in NSCLC.JCO, 2001,19,8:2123-2133.

6. Shintaro Tarumi et al.Pulmonary rehabilitation during induction chemoradiotherapy for lung cancer .J Thoracic and cardiovascular surg.February 2015,49, 2:569-573. 